\title{
Cenas brasileiras, violências, subjetividades
}

\author{
Brazilian scenes, violence, subjectivities
}

Meriti de Souza*

\begin{abstract}
Resumo: Neste artigo problematizamos as repercussões dos ideais sociais que retratam o povo brasileiro como pacífico e avesso a movimentos marcados por ações violentas. De forma específica, interessa problematizar as repercussões desses ideais sobre a organização social nacional e a constituição subjetiva do brasileiro. A pergunta posta diz respeito às implicações subjetivas e sociais relacionadas ao fato de uma pessoa inserida na tradição cultural nacional passar a se representar e a se sentir como alegre e pacífica, mesmo perante a desigualdade social e a violência. Entendemos que essa inscrição psíquica pode ocorrer em função do ideal social disseminado por séculos a fio, pelas elites que dominam a cena econômica e cultural.
\end{abstract}

Palavras-chave: Cenas brasileiras, Violências, Subjetividades.

\begin{abstract}
In this theoretical essay, it is possible to problematize the repercussions of social ideals that portray the Brazilian people as peaceful and averse to movements marked by violent actions. Specifically, it is significant to problematize the repercussions of such ideals on the national social organization and subjective constitution of the Brazilian citizen. The question posed concerns personal and social implications regarding the fact that a person inserted in the national cultural tradition starts to represent and feel like joyful and peaceful, even in the face of social inequality and violence. It is possible to understand that such psychic inscription may occur in function of the social ideal disseminated for centuries by the elites that dominate the economic and cultural scene.
\end{abstract}

Keywords: Brazilian scenes; Violence; Subjectivities.

\footnotetext{
* Professora na Universidade Federal de Santa Catarina, Florianópolis/SC, Brasil. Doutora em Psicologia Clinica na PUCSP. Pós-doutorado no Centro de Estudos Sociais - CES/Universidade de Coimbra. E-mail: meritisouza@yahoo.com.br
}

(c) EY Direito autoral e licença de uso: Este artigo está licenciado sob uma Licença Creative Commons. Com essa licença você pode compartilhar, adaptar, para qualquer fim, desde que atribua a autoria da obra, forneça um link para a licença, e indicar se foram feitas alterações. 


\section{Introdução}

Vários discursos presentes no cenário nacional sustentam representações sobre os brasileiros e as brasileiras como pessoas pacíficas e avessas a situações que envolvem mudança e transição. A história oficial sobre o país produz leituras sobre a constituição da nação, como a Independência, a Proclamação da República, a abolição da escravatura, por exemplo, como transições pacíficas, efetivadas por líderes com características de heróis. Essas leituras sustentam que a maioria dos episódios de transição na história do país teria ocorrido sem o envolvimento de ações agressivas. Ato contínuo, esses discursos sustentam ideais sociais que organizam modalidades de organização societária, bem como, estruturam modelos identificatórios produtores de específicas subjetividades.

Não obstante, apesar dos discursos dominantes na cena nacional sobre a passividade reinante, a violência encontra-se sempre em foco, tanto nas práticas e discursos que conformam o cenário social, quanto nas vivências e práticas cotidianas das pessoas. Importante salientar que apesar de ocupar lugar de destaque nos cenários públicos e privados o universo da violência revela-se ambivalente, pois, instiga a investigação e o falar sobre concomitante a expulsão das nossas vistas e o calar sobre. Possivelmente, a ambiguidade desse fenômeno também pode se associar a multiplicidade de configurações e materializações que ele assume e aos infindáveis espaços que ele ocupa. Também, o fascínio e a repulsa que ele exerce se associam ao abalo narcísico que provoca. Em outras palavras, como herdeiros do iluminismo e da ordem civilizatória acreditamos que o assomo das paixões explicita o que escapa ao mandato da razão e, dessa forma, supomos que controlamos atos e pensamentos violentos.

A partir desse cenário, interessa-nos problematizar as repercussões dos ideais sociais que retratam o povo brasileiro como pacífico e avesso a rupturas marcadas por ações violentas, concomitante ao expurgo da memória nacional desses componentes. De forma específica, interessa problematizar as repercussões desses ideais sobre a organização social nacional e a modalização subjetiva que predomina na rede social nacional. Investigamos essas questões a partir de dois movimentos analíticos: análise de discursos presentes na história nacional referentes à denominada passividade dos(as) brasileiros(as) em episódios que envolvem a busca pela autonomia da nação e análise das questões subjetivas envolvidas na construção e reiteração do fenômeno da violência no seu entrelace com o cenário cultural nacional. Dirigimos a esses discursos algumas perguntas: como se elaboram episódios que explicitam vivências de violência configuradas como representações desvalorizadas? Como se articula a subjetividade capturada por esses discursos? Como se organiza a violência na sua relação com a constituição subjetiva ¿ Para analisar essas questões trabalharemos neste artigo teórico com referências analíticas oriundas da psicologia, da história e da psicanálise. 


\section{Representações sobre brasileiros(as) e alguns cenários nacionais.}

Inicialmente, nossa tendência é a de relevar que as representações sobre a alegria e a passividade do povo brasileiro predominam na rede discursiva nacional. A título de exemplo, essas supostas características dos brasileiros e das brasileiras guindadas à condição de paradigma dos movimentos pela Independência Nacional, da República e mesmo da Abolição, colaram-se ao imaginário social, graças à força de disseminação da história oficial. A maior parte das pessoas acredita na representação que os designa como um povo alegre e pacífico; acredita que a escravidão foi revogada por uma bondosa princesa que desferiu um golpe de caneta (ou melhor, um golpe de pena); que garbosos príncipes e generais nos libertaram de Portugal e da Monarquia, sem derramarem uma gota de sangue, como convém a um povo pacífico e afetuoso. A história oficial cumpre a função de excluir os movimentos sociais que envolveram ações violentas e contradizem essa imagem idílica. Assim, a representação do povo pacífico e alegre, avesso a rupturas e a atos agressivos, oferece estratégias de controle simbólicas e subjetivas. Isso ocorre, principalmente, em decorrência da identificação da maioria das pessoas com esses atributos que passam a constituir a sua representação identitária e, portanto, o seu sentimento de identidade. Exemplificando, podemos considerar "idílicas" as imagens construídas acerca das rupturas em nossa história: por exemplo, o quadro de D. Pedro I ao proclamar a Independência, tendo um riacho ao fundo, garbosamente montado em seu cavalo e acompanhado de um cortejo que comemora o feito.

Entretanto, sabemos que a predominância desses discursos não corresponde a sua realidade, bem como, a captura das pessoas pelos ideais sociais não repercute de forma linear e total na constituição subjetiva. Sabemos que apenas a versão da história oficial disseminada não garante a elaboração e aceitação de uma representação, pela maioria da população. Senão, assumiríamos a crença de que as elites que disseminam esses discursos operam como o demiurgo da consciência nacional, atribuindo-lhe uma força simbólica hercúlea e estrutural. Assim, existiram e existem episódios marcados por ações agressivas e contestatórias, que questionam a representação da alegria e da passividade como hegemônicas na rede social brasileira.

Contemporaneamente, a representação persiste com uma adaptação aos novos tempos. Continuamos a nos considerar um povo alegre, simpático, amante do samba, do carnaval e do esporte, compondo nossa imagem de brasileiros e brasileiras felizes. Entretanto, acreditamos que o mito do povo pacífico e alegre, que "sorri até da desgraça", camufla outros conteúdos, como por exemplo, aqueles encontrados nas manifestações de revolta coletiva, presentes em nossa história ${ }^{1}$. Assim, concomitante a essa tradição cultural e simbólica nacional podemos acompanhar uma série de manifestações e de movimentos que a contradizem. A título de exemplo, podemos acompanhar ao 
longo da história nacional de forma inconteste manifestações de contestação e movimentos reivindicatórios dos mais diferentes matizes deflagrados pela população.

Consideramos a realidade da história mundial e da história nacional marcada por movimentos e ações de contestação e a intensidade das manifestações no tocante à agressividade ${ }^{2}$. Particularmente, na cena brasileira chama atenção à propalada atribuição da passividade e da alegria nacional Essa face alegre e passiva, não estaria exageradamente ampliada pelos parâmetros dos ideais sociais hegemônicos, escondendo outras que revelam faces diferentes?

As perguntas pertinentes em decorrência desse cenário dizem respeito a como o sujeito subjetivado pelos parâmetros dos ideais sociais hegemônicos, articula o que poderíamos chamar de modo de funcionar para além desses parâmetros. De que forma a vivência e exteriorização de características como a agressividade e a atividade se articulam a rede social brasileira, frente à predominância e valorização das representações de não violência e passividade?

Conforme anunciado anteriormente interessa-nos compreender a função exercida pela colagem de um determinado referencial identitário a produção subjetiva que opera na rede social brasileira. A pergunta posta diz respeito às implicações subjetivas e sociais relacionadas ao fato de uma pessoa inserida na tradição cultural nacional passar a se representar e a se sentir como alegre e pacífica, mesmo perante a desigualdade social e a violência. Assim, essa inscrição psíquica pode ocorrer em função do ideal social disseminado por séculos a fio, pelas elites que dominam a cena econômica e cultural. Supomos que esse ideal pode cumprir uma função, pois, as pessoas capturadas por esse referencial identitário podem desvalorizar aquelas que praticam ações qualificadas como agressivas, bem como, podem se sentirem compelidas a não exercerem essas ações. Assim, a função mencionada pode ser a de desestimular a eclosão de ações singulares e coletivas, que desestabilizem as representações de alegria e passividade ${ }^{3}$ Entretanto, referências como a psicologia e a psicanálise apontam que a violência acompanha a constituição subjetiva não obstante a força constitutiva posta pelos ideias sociais, principalmente aqueles que imputam mandatos identificatórios agregados a valorização da passividade. Vamos analisar as relações da constituição subjetiva com as violências.

\section{A violência e a constituição psíquica}

Pode ser muito inquietante, porém é necessário reconhecermos que o ser humano se encontra em condições de exercer a violência e, se restringe esse exercício é muitas vezes em decorrência de valorações e punições simbólicas e concretas construídas pelas redes sociais. Em outras palavras, as pulsões 
agressivas que impelem o humano para a ação também constituem o psiquismo. Por um lado, esse reconhecimento não significa em nenhuma hipótese a defesa das ações agressivas e, por outro lado, ele serve de referencial analítico para problematizarmos o locus subjetivo que sustenta essas ações. Conforme lembra Freud ${ }^{4}$ e Freire Costa ${ }^{5}$, considerar que aspectos violentos fazem parte da constituição subjetiva não significa atenuar o horror das ações realizadas por pessoas nas quais predominam impulsos destrutivos e violentos e exercem ações em nome do desejo de fazer sofrer ao outro. Entretanto, significa relevar que a o humano no plano coletivo e no plano singular necessitam recorrer a valores éticos (filosóficos, culturais, religiosos) e mesmo a sanções e punições, para controlar e cercear seus impulsos violentos e destrutivos. Essa leitura sobre a dualidade da constituição do humano nos permite compreender a dificuldade em discriminar o exercício da violência em nome de uma ação defensiva, daquela ação executada a partir de um excesso e de um desejo de dominação sobre o corpo e o desejo do outro. Ainda, essa leitura também nos permite compreender o fascínio exercido pela violência sobre a maioria das pessoas, inclusive aquelas que ocupam lugares profissionais destinados a prevenir ações agressivas e cuidar do daqueles que sofrem e/ou que exercem essa ação.

Acreditamos que de forma particular o fenômeno da violência desestabiliza a concepção idealizada da subjetividade como restrita à consciência, pois faz eclodir uma realidade que acompanha o ser humano no seu percurso civilizatório, da filogênese a ontogênese, do ancestral animal ao denominado homo sapiens. Assim, a concepção psicanalítica sobre o sujeito como constituído por uma subjetividade cindida na qual a razão acompanha as pulsões e o inconsciente, revela-se importante de ser trabalhada.

A concepção da violência como necessária à constituição da subjetividade encontra-se presente no cenário psicanalítico. Segundo Aulagnier ${ }^{6}$ a mãe ou pessoas responsáveis pela criança engendram sobre ela uma modalidade de violência denominada primária. Para a autora essa modalidade é necessária à constituição subjetiva das pessoas e diz respeito à inscrição do sujeito na rede simbólica estabelecida a priori, ou seja, refere-se a práticas e a linguagem pré-existentes ao nascimento da criança. Entretanto, a autora alerta que dependendo das condições psíquicas do ambiente no qual a criança é cuidada, outra modalidade de violência desnecessária e nociva pode ser engendrada. A essa modalidade a autora denomina violência secundária. Duvidovich ${ }^{7}$ desenvolve um trabalho onde remete à distinção entre dois aspectos da agressão: um referente à agressão necessária a constituição do sujeito psicológico e outro referente a um excedente, associado à destrutividade. A constituição do sujeito é associada a um processo invasivo, prenhe de violência, que lhe possibilita a apreensão do real e da existência do outro. Para Ceccarelli ${ }^{8}$ a violência, individual ou coletiva, funciona como uma "solução", uma saída 
aos problemas de identidade. A renúncia à satisfação pulsional, decorrente da organização social moderna, pode levar o psiquismo a procurar outras formas de satisfação associadas à violência. Para o autor, algumas práticas violentas funcionam como formações substitutivas, possibilitando que os componentes agressivos das pulsões recalcadas possam ser descarregados.

Para Hannah Arendt ${ }^{9}$ a violência pode ser entendida como a incapacidade do sujeito em se identificar com a dor e o sofrimento dos outros, ou seja, aquele que age de forma violenta seria incapaz de posicionar-se no lugar ou ao lado daquele que sofre os efeitos violentos. Quando analisa o processo de Eichmann Em Jerusalém é possível entendermos que a autora refere-se a este sujeito como ocupando esse lugar de incapacidade, pois, o compreende como um burocrata que seguia ordens e não como um "monstro" que se diferenciasse da maioria dos homens ${ }^{10}$.

A autora cunha o conceito de "banalidade do mal" para se referir à presença da violência na vida cotidiana de pessoas capturadas pela engrenagem da burocracia, da hierarquia e do poder. A violência emerge nas pequenas e corriqueiras ações permeadas pela crueldade. A banalização do mal nos põe face a face com a violência exercida e sofrida por pessoas comuns e obedientes aos mandatos da ordem civilizatória contemporânea, marcada pela hierarquia e impessoalidade nas relações de trabalho, laser, afetivas e políticas.

A concepção sobre a violência como necessária à constituição da subjetividade encontra-se presente no cenário psicanalítico. A renúncia à satisfação pulsional, decorrente da organização social moderna, pode levar o psiquismo a procurar outras formas de satisfação associadas à agressividade. A violência como formação substitutiva possibilita que o sujeito extravase as pulsões agressivas recalcadas. Esta é a tese apresentada por Freud ${ }^{11}$ em Mal Estar na Civilização.

A existência da inclinação para a agressão, que podemos detectar em nós mesmos e supor com justiça que ela está presente nos outros, constitui o fator que perturba nossos relacionamentos com o nosso próximo e força a civilização a um tão elevado dispêndio [de energia]. Em consequência dessa mútua hostilidade primária dos seres humanos, a sociedade civilizada se vê permanentemente ameaçada de desintegração. [...] A civilização tem de utilizar esforços supremos a fim de estabelecer limites para os instintos agressivos do homem e manter suas manifestações sob controle por formações psíquicas reativas.

Para Freire Costa ${ }^{12}$ na psicanálise freudiana, "não existe um instinto de violência. $\mathrm{O}$ que existe é um instinto agressivo que pode coexistir perfeitamente com a possibilidade do homem desejar a paz e com a possibilidade do homem 
empregar a violência". O autor critica a leitura que naturaliza a violência ao pressupor um instinto violento na gênese da cultura e da constituição subjetiva. Freire $\operatorname{Costa}^{13}$ pontua que a violência é marcada pela gratuidade de sua manifestação, ou seja, ela não se associa à defesa do agressor nem à manutenção de seu bem-estar. A violência gera em sua vítima um desprazer desnecessário, viola as regras estabelecidas pelo social e configura o emprego desejado da agressividade. Entretanto, Freire Costa ${ }^{14}$ defende a tese de que a violência não opera como fundante da cultura, bem como, também afirma que não existe uma sobreposição entre poder e violência. $\mathrm{O}$ autor analisa essas questões a partir do trabalho de Arendt ${ }^{15}$, pois, essa autora afirma que para se autorizar o poder demanda o consentimento de um grupo e a elaboração de um contrato social entre aqueles que se consideram iguais. Essa leitura pressupõe que o poder opere entre pessoas que estabelecem interesses comuns e definem leis gerais. Assim, para Freire Costa e Arendt, os interesses que abrangem a universalidade agrupam as pessoas em redes sociais configurando a coesão do grupo e o estabelecimento de normas e de acordos. Em contrapartida, para esses autores a violência não opera como fundante do grupo ou da sociedade, ainda que possa atravessar as redes sociais. Em outras palavras, o que permite a coesão grupal e o estabelecimento das sociedades são os acordos e as leis construídos a partir de interesses comuns e não necessariamente a violência exercida de um sobre o outro.

Os argumentos dos autores nos auxiliam problematizar a condição que nos leva a encarar o fenômeno da violência de forma única e exclusiva a partir da posição passiva. A psicanálise possibilita entender as engrenagens entre a constituição psíquica da lei e o mito do parricídio para encararmos as relações entre ativo e passivo, entre cultura e natureza, no sentido das pulsões que constituem o humano. Com estas afirmações queremos problematizar a posição narcísica e idealizada que atribui o fenômeno da violência ao outro, ao bárbaro, a natureza, bem como, a posição naturalista que atribuí a constituição da cultura ao exercício desse fenômeno. Por um lado, a posição naturalista pode justificar a manutenção desse fenômeno na rede social em decorrência da trajetória evolutiva do ser humano e, por outro lado, a posição idealizada pode justificar a posição exclusiva de vítima frente a esse fenômeno. Entendemos que o ser humano não se configura de forma exclusiva no "lobo do homem", bem como, não se constitui de forma dicotômica no algoz ou na vítima do ato violento. As relações do humano com a violência no plano universal da cultural e no plano singular da constituição subjetiva se revelam complexas e merecem atenção.

Para Freud ${ }^{16}$ a agressividade é um instinto e inerente a vida humana, entretanto, ela não se articula ao desejo, configurando antes uma ação natural. Acompanhando as análises de Freire Costa podemos entender a violência como o emprego desejado da agressividade, ou seja, ela se relaciona com o 
desejo de destruir. Como a violência se articula a constituição subjetiva, ao desejo e a vontade ela é um processo humano, pois, os animais apenas lidam com suas necessidades e seus instintos biológicos. Assim, o autor pontua a agressividade como associada à necessidade e ao fator biológico. A violência é associada à ordem da gratuidade da vontade e do psiquismo humano sendo que seu emprego produz um desprazer desnecessário ao outro e extrapola as regras sociais.

Conforme afirmamos anteriormente a violência encontra-se sempre em foco, tanto nas ações e discursos que atravessam o cenário social, quanto nas nossas leituras e nossas pesquisas. Também, conforme afirmamos anteriormente nossa tradição iluminista e nosso narcisismo nos levam a acreditar no pleno controle da pulsão e do inconsciente pela razão e pela ciência. Assim, o sujeito sujeitado e substantivado da/pela lógica formal e identitária que usufruía com a grata satisfação narcísica de corresponder à demanda da razão e da consciência que organizam a vida societária vê-se confrontado com o que escapa, com o pathos, com o inconsciente, com o resto ${ }^{17}$. Esse confronto desestabiliza e assusta, pois explicita o humano demasiado humano. Assim, o resto que a violência encarna e explicita se associa ao excluído e escandido da ordem civilizatória que entroniza tanto a razão e a ciência como forma predominante de produzir conhecimento quanto à subjetividade restrita a consciência como modelo exclusivo de único de subjetivação ${ }^{18}$.

Importante salientar neste artigo que o conceito de simbólico pode ser pensado no sentido antropológico e histórico de representações elaboradas a partir das práticas e dos discursos que circulam no cenário social. Assim, simbólico diz respeito a narrativas sobre a trajetória e a organização de um grupo social, que ganharam hegemonia e predominam na rede discursiva e práticas sociais.

Entretanto, o referencial freudiano também nos possibilita reconhecer o trabalho da inscrição psíquica e sua mobilidade, frente à diferença singularizada dessa inscrição no plano do simbólico definido como representação de palavra. Conforme sabemos o singular da subjetividade encarna um fantasma, um desejo, um corpo, um inconsciente. Assim, quando falamos de brasileiros, não existe um fantasma, um inconsciente, um corpo, que sustente a leitura sobre uma dada subjetividade brasileira. Frente a esse problema pensamos no trabalho de pesquisa como referenciado na constituição do sujeito que se apropria da cena coletiva e singulariza a consciência e o inconsciente. Por um lado, sabemos que a apropriação singular do coletivo realizada pelo sujeito envolve as experiências e afetos possíveis de serem metabolizados e representados, bem como, também envolve àqueles que escapam à ordem representacional. Por outro lado, o recorte teórico incide no plano representacional e simbólico, a considerar que ele se imbrica a constituição subjetiva. 


\section{Algumas análises finais}

A irrupção do estranho, do diferente, do estrangeiro, na história nacional sempre foi sufocada ou excluída: as revoltas, as rebeliões, as vozes dos excluídos foram desqualificadas, esquecidas. Essas vozes e esses fatos amedrontavam e desestabilizavam o instituído e, no seu lugar erigiu-se a história e o discurso oficial; a lei e a instituição. Porém, mais sutil e funcional do que esse mecanismo foi à construção da representação de que somos um povo pacífico e alegre, que vive o diferente e o aceita, chegando ao extremo de encarnar a própria diferença .

A discussão sobre o fenômeno da violência não pode ser restrita a determinados cenários e determinadas pessoas. Antes, faz-se necessário referenciar a existência desse fenômeno em toda a história humana e presente em todas as camadas culturais, sociais e econômicas da população. Assim, essa leitura permite construir um importante raciocínio sobre o temor e o concomitante e paradoxal fascínio das pessoas no trato com esse fenômeno. Acreditamos que devido à sua complexidade e devido à sua intensa repercussão no psiquismo humano, a violência comporta a peculiaridade de apresentar uma extrema dificuldade para o seu reconhecimento e para o trabalho com ela e com os envolvidos, seja na condição de agressor ou de agredido.

Entretanto, consideramos importante relembrar que as pessoas se encontram inseridas na rede social e histórica contemporânea, o que significa que elas se constituem no plano emocional e cognitivo a partir desse solo coletivo sendo, portanto atravessadas pela violência que se encontra entranhada nas redes sociais e históricas. As pessoas são configuradas no plano singular da sua vida emocional e cognoscente a partir das expressões coletivas de opressão e violência, que conformam a rede capitalista e liberal contemporânea. Assim, elas se constituem a partir dos efeitos da violência simbólica e psicológica, ainda que necessariamente não tenha vivenciado o ato violento físico.

As relações entre a epistemologia e a ontologia e a prática social são imediatas e evidenciam as concepções sobre constituição subjetiva, método, ação social, adotadas pelo pesquisador e pelo profissional das mais diversas áreas. Entretanto, a crescente separação do conhecimento em áreas produz o isolamento dos profissionais em nichos conceituais e técnicos concomitante a filiações autorais institucionais que obliteram o trabalho do pensamento. Esse contexto possibilita que teorias sejam naturalizadas e inviabiliza o trabalho crítico necessário a demanda posta pela pesquisa e pela produção do conhecimento.

A junção entre poder e saber foi reiteradamente denunciada por Foucault e, sabemos como o último pode dizer respeito ao estabelecimento de hierarquias em detrimento ao conhecimento crítico. Nessa perspectiva, o que escutamos quando ouvimos sobre os estereótipos relativos à passividade e a cordialidade de brasileiros e brasileiras $₫$ O que escutamos quando ouvimos discursos referentes 
à transição pacífica ocorrida em cenas históricas nacionais ¿ As possibilidades se abrem se pensarmos nas modulações subjetivas como articuladas a modos de subjetivação coletivos, ou seja, a configuração psíquica se articula a práticas e discursos que atravessam determinados espaços e tempo e configuram subjetividades que tanto se assujeitam quanto resistem aos mandatos dos ideais identitários. A questão está na demanda posta como norma coletiva e produzida como desejo singular pela subjetividade que, no próprio movimento de retorno sobre si engendrado pela consciência auto-reflexiva configura o desejo marcado pelo assujeitamento e pela resistência. Butler trabalha essa questão quando analisa as relações entre o psiquismo e o poder e, explicita sua leitura quando nomeia seu trabalho como estudo e pesquisa sobre a vida psíquica do poder.

Associar a relação da violência com o estereótipo da passividade e da cordialidade nacional não oferece possibilidade para lidar com o sintoma, mas antes com o fenômeno. Necessário salientar que não estamos a dissociar a manifestação sintomática e singular do plano fenomênico, mas antes, a chamar atenção à associação imediata entre a construção de ideais sociais e a apropriação subjetiva desses ideais. Os sentidos de passivo e de alegre agregados as práticas sociais operam como referencial identitário para a maioria do povo brasileiro. Porém, por um lado esses sentidos não dizem respeito de forma genérica e imediata a elaboração subjetiva das pessoas e, por outro, o movimento da subjetivação que acompanha as modulações do modo de subjetivar que predomina no cenário atual explicita a associação do sujeito a um determinado recorte espacial e temporal. Ato contínuo, os brasileiros e as brasileiras ao recorrerem ao significante passividade e alegria enunciam-se como passivos e alegres e explicitam sua inscrição psíquica em determinada tradição histórico, cultural e simbólica, bem como, explicitam sua relação com os sentidos encarnados nesses conceitos.

Conforme afirmamos anteriormente é difícil reconhecermos que as pulsões agressivas também constituem o psiquismo, assim como instrumentalizam as pessoas para agir sobre o real construindo civilização e cultura. Também afirmamos anteriormente que esse reconhecimento não implica a defesa de atos violentos e que serve de referência para analisarmos a constituição subjetiva das pessoas. De qualquer forma, acreditamos ser pertinente manter a perspectiva apresentada acima para não adotarmos leituras maniqueístas e idealizadas sobre o humano que o concebem como o "bom selvagem" corrompido única e exclusivamente pelas forças sociais. Essa leitura é necessária para podermos nos aproximar da complexidade do fenômeno da violência e, mesmo, da dificuldade das pessoas no seu reconhecimento e no trato com ela. Supomos que tal situação decorra, entre outros aspectos, justamente da negação desse fenômeno como um aspecto constitutivo do humano. Essa decorrência faz com que a maioria das pessoas desenvolva uma concepção moralista sobre esse aspecto e procure de forma imediata 
negar a sua presença na cena familiar e nas práticas das pessoas próximas e mesmo nas suas.

A considerar essas questões, reiteramos nossa concepção de que é produtivo problematizar os aspectos afetivos e subjetivos envolvidos no fenômeno da violência e, de forma particular, analisar os limites de ações articuladas no plano das concepções políticas que se restrinjam a considerar o sujeito como configurado pela subjetividade sobreposta de forma única e exclusiva à consciência e a razão. Esses questionamentos podem redundar na análise que aponte à necessidade de construirmos ações políticas que incorporem novas estratégias de ação que relevem os aspectos não explicitados e mesmo, negados e recalcados da vida pública e moderna: a saber, a configuração pulsional e afetiva do humano.

Assim, a partir desse cenário teórico podemos entender como os sujeitos orientados pelos atributos da passividade e da alegria concernentes aos ideais sociais postos a circular na cultura nacional, produzem e explicitam o que poderíamos chamar de características antagônicas as representadas como constitutivas da sua identidade. Conforme sabemos os processos de captura identificatórios não operam de forma total e a possibilidade de externar a tristeza e a violência, por exemplo, pode acontecer em momentos de grande comoção nacional, onde, a cobrança pela alegria possa ser "atenuada" em decorrência da perda de símbolos a ela relacionados ou de situações de exceção. Que possibilidade melhor para poder questionar o status quo e de exercer ações e movimentos reivindicatórios do que perder a representação de passividade e de eterna alegria que se encontra colada a cara dos brasileiros e das brasileiras?

Reiteramos a afirmação de que o nosso interesse com esta discussão é questionar o processo produtor de formas de subjetivar calcados em referenciais identitários e configurações subjetivas restritas e pré-determinadas, pois, os consideramos substratos psíquicos do sistema liberal e do modo de dominação simbólica das elites nacionais. Ressaltamos a concepção de que a configuração subjetiva opera no plano do devir e consideramos produtivo problematizar a constituição de subjetividades pautadas pelo dever ser a partir de determinados atributos ou características. Assim, as demarcações identitárias presa a ideais sociais operam como aliadas da ordem estabelecida e o trabalho de problematizar e expor essa forma de operar pode se revelar profícuo no caminho da produção de novas redes sociais e configurações subjetivas.

\section{Notas}

1 SOUZA, M. A experiência da lei e a lei da experiência- ensaios sobre práticas sociais e subjetividades no Brasil. Florianópolis: Editora da UFSC, 2016.

2 CHESNAIS, J.-C. Histoire de la violence en Occident de 1800 à nos jours. Paris, Robert Laffont. 1981. 
MAFFESOLI, M. Dinâmica da Violência. São Paulo, Editora Revista dos Tribunais, Edições Vértice, 1987.

HOBSBAWM, E. Globalização, democracia e terrorismo. São Paulo: Companhia das Letras, 2007.

HOBSBAWM, E. (1998) As regras da violência. In: Pessoas extraordinárias: resistência, rebeldia e jazz. São Paulo: Ed. Paz e Terra, 1998.

PAULI, M.C. et alii. A Violência brasileira. São Paulo, Brasiliense, 1982.

3 Bresciani, em um trabalho sobre a emergência das multidões em meio ao processo de consolidação do mundo burguês, procura dar visibilidade aos pobres e marginalizados de Londres e Paris, no século XIX. A autora nos mostra como o espetáculo da pobreza chocava e enchia de terror a burguesia, produzindo o medo da emergência das multidões. Analogamente, podemos pensar num mecanismo parecido a operar junto ao imaginário nacional das elites no Brasil: o medo da multidão enraivecida pela injustiça social e econômica. Assim, um mecanismo que constrói a imagem do brasileiro como alegre e simpático, pode ajudar a conjurar o medo da revolta e da agressividade do revoltoso.

BRESCIANI, M.S.M Londres e Paris no Século XIX: o Espetáculo da Pobreza. São Paulo: Brasiliense, 1982.

4 FREUD, S. Mas alla del principio del placer. Biblioteca Nueva: Madrid, 1973.

FREUD, S. Nuevas lecciones introductorias al psicoanalisis. Madrid: Biblioteca Nueva, 1973.

5 FREIRE COSTA, J. Violência e psicanálise. Rio de Janeiro: Graal, 1986.

6 AULAGNIER, P. A violência da interpretação. Rio de Janeiro: Imago, 1979.

7 DUVIDOVICH, E. Violência e subjetivação. Boletim de Novidades da Livraria Pulsional, São Paulo, ano XI, n. 108, p. 41-6, abr/1998.

8 CECCARELLIi, P. R. Delinqüência: resposta a um social patológico. Boletim de Novidades da Livraria Pulsional. São Paulo, ano XIV, 145, 5-13, maio, 2001.

9 ARENDT, H. Da violência. In: Crises da república. São Paulo: Perspectiva, 1973.

10 ARENDT, H. Eichmann Em Jerusalém - Um relato sobre a banalidade do mal. Companhia das Letras, 1999.

11 FREUD, S. O mal-estar na civilização. In: Edição Standard Brasileira das Obras Psicológicas Completas de Sigmund Freud. Vol. XXI. Rio de Janeiro: Imago, 2002, p. 70.

12 FREIRE COSTA, J. Violência e psicanálise. Rio de Janeiro: Graal, 1986, p. 27.

13 COSTA, JF. Transcendência e violência. In JACÓ-VILELA, AM., and SATO, L., orgs. Diálogos em psicologia social [online]. Rio de Janeiro: Centro Edelstein de Pesquisas Sociais, 2012. p. 87-102.

14 FREIRE COSTA, J. Violência e psicanálise. Rio de Janeiro: Graal, 1986.

15 ARENDT, H. Da violência. In: Crises da república. São Paulo: Perspectiva, 1973.

ARENDT, H. Eichmann Em Jerusalém - Um relato sobre a banalidade do mal. Companhia das Letras, 1999.

16 FREUD, S. Além do princípio do prazer. Obras completas, vol. XVIII. Rio de Janeiro: Imago, 1974. 
FREUD, S. O problema econômico do masoquismo. Obras completas, vol. XIX. Rio de Janeiro: Imago, 1974.

FREUD, S. Por que a guerra? Obras completas, vol. XXII. Rio de Janeiro: Imago, 1974.

17 BIRMAN, J. Cadernos sobre o mal: agressividade, violência e crueldade. Rio de Janeiro: Civilização Brasileira, 2209.

ENRIQUEZ. De la horde à l'État: essai de psychanalyse du lien social. Paris: Gallimard, 1983.

18 MORIN, E. O Método III: o conhecimento do conhecimento. Porto Alegre: Sulina, 2005a.

MORIN, E. O Método IV: as idéias. Porto Alegre: Sulina, 2005b.

PRIGOGINE, I. O fim das certezas: tempo, caos e as leis da natureza. São Paulo: Editora da Universidade Estadual Paulista, 1996.

PRIGOGINE, I. \& STENGERS, I. Entre o tempo e a eternidade. São Paulo: Companhia das Letras, 1992.

SOUSA SANTOS, B. Um discurso sobre as ciências. São Paulo: Cortez, 2005.

19 SOUSA, O. Fantasia de Brasil. São Paulo: Escuta, 1994.

20 FOUCAULT, M. Microfísica do poder. Rio de Janeiro, Graal, 1979.

FOUCAULT, M. As palavras e as coisas. Rio de Janeiro, Graal, 1990.

21 BUTLER Problemas de Gênero - Feminismo e subversão da identidade. Rio de Janeiro: Civilização Brasileira, 2003.

Recebido em 27/06/2018

Aprovado em 29/09/2018 